the Secretary of the Society for the efficient method in which he has conducted the work of his office, arduous and exacting as it has been, and to the Directors and Councilors of the Society for the support which they have given me in all matters connected with the executive conduct of the presidential office.

In the little which I myself have been able to do, I have had in view only one object; viz., the welfare and prosperity of the Society. It may be that in some cases offence has been given to members of the Society by the manner in which my work has been done, but I am sure that those who have intimate knowledge of the motives which have actuated my conduct will bear witness to the fact that such offence was not given with malice or meaning.

To my successor I may say that he will find the officers, councilors, and directors, remaining as they do mostly unchanged, full of zeal in the work of building up the Society and ready at all times to support him in the conduct of his office.

\title{
THE DETERMINATION OF PHOSPHORIC ACID.
}

BY H. PEMBLRTOX, JK

Kereiverl fantary $1 \overline{7}, 895$

T

$\mathrm{HE}$ method of determining phosplioric acid by the alkalimetric titration of the yellow precipitate, has been employed, lately, by a number of chemists and has been made a subject of investigation by the Association of Official Agricu1tural Chenists. A report upon the subject has been embodied in its last bulletin.

There are a few points regarding this method to which attention should be drawn.

In preparing the standard alkali its strength is, of course, established by testing it against acid of known strength. In doing this, it is important that the indicator used should be phenolphthalein, and not methylorange. Potassium hydroxide almost invariably contains alumina, and such a solution gives the neutral reaction with methyl orange before it gives it with phenolphthalein. Consequently if methyl orange is used in the standardizing and phenolphthalein is used in the titration of the 
yellow precipitate, too much of the alkali will be used in the latter case, and the results will be high.

The same reasoning holds true in case a little carbon dioxide is present in the alkali.

In regard to the precipitation of the phosphoric acid by the aqueous solution of the molybdate, the following directions were given: Heat is now applied, and the solution brought to a full boil. It is then removed from the lamp, no more heat being applied. (This JoURNAL, 15, 387.)

I have italicized here in order to draw attention to this point. If the volume of the phosphate solution is from fifty to seventyfive cc., it will be found, after adding five cc. of the molybdate, say three times (fifteen $\mathrm{cc}$. in all) that the temperature of the solution will be about $70^{\circ} \mathrm{C}$., which is about the proper temperature for the precipitation. In other words, the solution, once heated, will take care of itself, (if I may use the expression) and does not require a water-bath of definite temperature, or any testings with the thermometer.

There is another point in connection with this precipitation that is of interest. It is well known that a precipitate that has a crystalline or coarse structure is more easily washed, and is less liable to carry down impurities, than a precipitate obtained in a finely divided condition, or as a "mud." Thus in separating lime as sulphate, from iron and alumina, in Jones' process, the alcohol is not added until most of the calcium sulphate has crystallized out from the aqueous solution. Were the sulphuric acid added to the alcoholic solution the precipitate would certainly be impure. In like manner, in potassium determinations, we evaporate the solution nearly to dryness (although it takes this extra time), in order to obtain the platinum salt in a crystalline state. Again in precipitating phosphoric acid by magnesia mixture, the latter is added slowly, drop by drop, "stirring vigorously," in order to prevent contamination. In the same way, when precipitating by the aqueous molybdate, I am accustomed to run the contents of the five $\mathrm{cc}$. pipette into the solution not in one continuous stream, but by interrupting the flow from the pipette by momentarily touching the end of the pipette with the finger, stirring the solution as it goes in. Thus 
the precipitate does not come down $\epsilon n$ bloc, in presence of a great excess of molybdate, but forms in a solution that is comparatively bare of molybdenum until the precipitate is nearly all down. The washing of the precipitate is best conducted, with the use of a vacuum, on a Hirsch porcelain funnel, smallest size, or as described by Mr. B. W. Kilgore, on a porcelain disk, (the disk to be covered with filter paper) with rubber rim in three inch glass funnel. In either case, soft paper from cut filters is better than that bought in sheets. Others have used the Gooch crucible, with advantage. With the Hirsch funnel I find that a precipitate containing forty mgms. of phosphorus pentoxide is thoroughly washed by $300 \mathrm{cc}$. of water. I may say here that fifty mgms. of phosphorus pentoxide is about the largest quantity that it is well to work upon, when employing a suction-pump. Chemists who do not use suction had better employ not more than thirty to forty minus. The phosphomolybdate is a difficult precipitate to wash, being like lead chromate in this respect.

The nitric acid, sp. gr. one and four-tenths, and the ammonium nitrate solution, are best kept in graduated glass cylinders of 200 to $300 \mathrm{cc}$. capacity, the mouths of which are kept covered by small beakers. The quantity desired to be poured out can then be read off on the graduation.

The molybdate solution (which should be neutral, and is best freed from any insoluble molybdic acid by filtration), can be kept in an ordinary narrow-mouth bottle. A wide, flat cork covers the mouth of this bottle, and through the center of this cork the stem of a five cc. volume pipette is held tight. This pipette rests, when not in use, in the molybdenum solution, and the cork prevents the entrance of dust. Mr. Kilgore has applied the ordinary nitric acid solution of the molybdate, to this volumetric process, with good results. He heats the solution on a water-bath having a constant temperature of $60^{\circ} \mathrm{C}$. Mr. F. Bergami adds to his solution of the phosphate (containing already about three cc. of strong nitric acid), ten cc. of ammonia, $\mathrm{sp} . \mathrm{gr}$. 0.90 , and then fifteen cc. of nitric acid, sp. gr. I.4O, and then, after heating to boiling, proceeds with the aqueous molybdate, in the usual way. Mr. L. A. Voorhees, precipitates with the nitric acid solution of the molyb- 
date in the cold, allows to stand, at the temperature of the room, over night, and titrates in the morning. The details of these modifications are given in the 1894 report of the Association of Official Agricultural Chemists, published at Washington, D. C. Whatever modification may be used, the volumetric method will be found much quicker than the gravimetric, and, after a little experience, fully as reliable.

Philanflphia, Pa.

\section{ON THE ESTIMATION OF SULPHUR IN PYRITES.' \\ BY G. LUNGE. \\ Received December 20 . 1894 .}

I NDER the above title, Mr. T. S. Gladding ('This JournaL, June, I 894), has published several modifications of the wet assay of pyrites which call for some comment on my part, since these modifications purport to be improvements on my method, contained in the "Alkali-makers' Handbook," and extensively employed in all countries.

Some of Gladding's modifications are of a less important character, and these can be passed in review very briefly. He does not, like myself, test the sample with its natural moisture, estimating the latter in a special sample, but he dries the whole sample and weighs it out in that state. He employs a whole gram of pyrites, I only half a gram; and I do so purposely, because the washing of the precipitates is much easier, and consequently the results are more reliable with the smaller than with the larger quantity. In lieu of the mixture of acids employed by me (three volumes of nitric acid of sp. gr. 1.42 and one volume of fuming hydrochloric acid) Gladding decomposes the pyrites with a solution of bromine and nitric acid. The prescription for that solution is not correct as printed, for seventyfive grams of potassium bromide can not possibly be dissolved in fifty grams of cold water, or anything like that quantity, but this may be a clerical error, which does not matter very much, as ultimately the solution is diluted to $500 \mathrm{cc}$. I will say at once that the bromine solution works well, but no better than the acid mixture according to my prescription.

1 Read at the Boston Meeting, December 28, 1894 . 